\section{GMAG: Stormy weather ahead?}

\section{8 may prove to be a difficult year for Britain's Genetic Manipulation Advisory Group. David Dickson reports}

GMAG, which was set up by the UK Government following concern at the implications of research into the genetic manipulation of microorganisms, celebrated its first birthday last month, thereby reaching the halfway stage of its first term of office. So far both scientists and trade unionists have given it, in general, a clean bill of health; comments on its performance range from "as good as could be expected" through "better than anticipated" to "a highly successful experiment"

Applications for more than 80 experiments, from about 25 different institutions, have been received, and all have been approved. According to Sir Gordon Wolstenholme, director of the CIBA Foundation and chairman of GMAG, the first year has been "surprisingly profitable and useful".

Yet if the first year has been relatively calm, there are storm clouds on the horizon. Two factors in particular are likely to put pressure on GMAG's activities in the near future, and to test its skill in treading a delicate path between different-and sometimes opposing-interest groups.

The first of these factors is industry's rapidly growing awareness of the financial rewards offered by genetic engineering techniques, from the production of artificial hormones to, possibly, new plant crops. Already seven major US companies have established recombinant DNA research laboratories, and several British companies, after a relatively slow start, are jumping on the band-wagon.

The second factor is the additional knowledge, both about genetic structures and the potential hazards of their manipulation, that has emerged in the four years since a temporary moratorium was first suggested by US scientists. This knowledge suggests that some of the initial reaction was overcautious, and that current guidelines might be "safely" relaxed.

Of these two, it is the industrial applications that have so far impinged most directly on GMAG's activities, primarily through the issues of confidentiality. For genetic engineering is rapidly becoming a field in which the dividing line between science and commerce is frequently indistinguishable.

In the US, for example, shortly after a team of San Francisco scientists headed by Dr Herbert Boyer confirmed that it had successfully inserted into bacteria a gene capable of producing the hormone somatostatin, a small Californian company Genentech an- nounced that it would be using the technique to produce somatostatin for sale to research organisations and pharmaceutical companies by mid-summer 1978 , at a cost considerably below the current market price.

In Britain, the National Research and Development Corporation-the body responsible for patenting and exploiting the results of governmentsponsored research-recently held a lively and well-attended meeting for university scientists on the potential applications of genetic engineering. NRDC has already awarded a research contract to the John Innes Institute near Norwich for the study of improvements in the production of the antibiotic streptomycin, and other projects are in the pipeline.

Although some companies, such as ICI, have been studying the applications of genetic engineering techniques for a number of years, little is publicly known about how far such work has progressed. For with the potential rewards so enormous, not only commercial companies, but all those with potentially-patentable techniques, are keen to play their cards as close as possible.

There is therefore an inevitable reluctance to reveal even in outline details of future research programmes to a group such as GMAG over whose use of the information-notwithstanding the Official Secrets Act-an individual company can exercise no direct sanction.

The confidentiality issue is one which the difficulty of reconciling "health and safety" factors against "national interest" has provided GMAG with some uncomfortable moments. In particular, the four trade union representativestwo from the Association of Scientific, Technical and Managerial Staffs (ASTMS), one from the Institute of
Above: view of E. coli by scanning electron microscope; right: researchers working in a high containment laboratory
Professional Civil Servants, and the medical officer of the Trade Union Congress - while respecting the need to maintain confidentiality for commercial reasons, have refused to be bound by any secrecy agreement which might prevent them from serving the interests of their members.

Many hours of discussion have been spent trying to devise a formula by which secrecy can be guaranteed for research programmes which must soon, under new health and safety legislation, be reported to the Health and Safety Commission. Eventually a compromise formula has been agreed under which, for a trial period of six months, members of GMAG will agree to a simple secrecy pledge, and applications for commercially-sensitive experiments will be seen by all except those considered to have some direct interest.

But for most scientists, the confidentiality issue, apart from interfering with claims for scientific precedence, remains largely peripheral. of far greater concern is the type of pressure that may be put on those responsible for maintaining safety guidelines as a result of industry's interest.

In particular, many fear that industry's desire to pursue and exploit the applications of such research as quickly as possible may result either in pressure on governments to reduce containment requirements too far, or to remove them altogether, leaving the management of risk to the vagaries of the market place (and the accountancy skills of insurance companies).

There are already pressures from scientists themselves to rationalise present containment levels, bringing them more in line with procedures adopted for other types of experiment using known pathogens, and taking into account both the development of new genetic engineering techniques and of more precise assessments of hazards.

Research by Professor Roy Curtiss at the University of Alabama in the US, for example, has confirmed that the K-12 strain of Escherichia coli

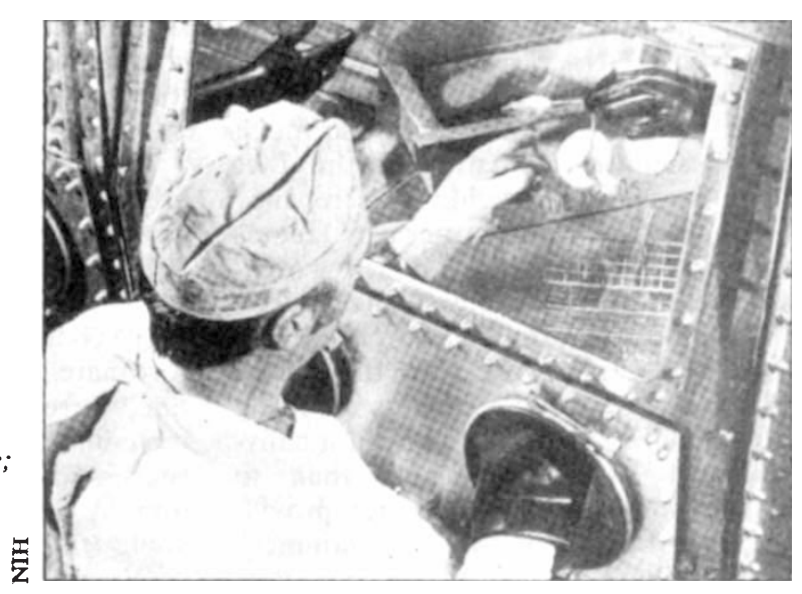


most commonly used in present recombinant DNA research is unable to survive in the human intestine like normal strains, and is thus very unlikely to cause an epidemic if it escaped from the laboratory.

This research has also led to the development of a "disabled" strain X1776 which has already been passed by GMAG for some high-risk experiments. And it is widely expected that the successful development of a hostvector system using another "disabled" strain of $E$. coli with equally "safe" properties will be announced soon in the UK.

Such developments are already encouraging a certain relaxation of physical containment levels, in particular since the greater the biological safety of the organism, the lower the nccessary degree of containment. In the US, for example, the National Institutes of Health published last summer proposed revisions to the guidelines first issued in June 1976. The new draft guidelines, which were publicly debated in Washington just before Christmas, and have already aroused considerable opposition from environmentalist groups such as Friends of the Earth, involve a considerable reduction in the containment levels for certain widely-used experiments.

Perhaps the most controversial proposal is to reduce the required physical containment level for experiments using recombinant DNA from mammals other than primates from $\mathrm{P} 3$ to $\mathrm{P} 2$; in practice this means that experiments using, say, mouse DNA which under the current regulations require purpose-built facilities, could be carried out on an open laboratory bench with a few relatively minor adaptations.

At present it is uncertain whether this particular proposal will be accepted (although others, such as a revised system defining physical containment requirements, probably will). Certainly many British scientists feel that, in the present state of knowledge, this may be relaxing things a little too far, at least for "shot-gun" experiments using unpurified DNA.

Yet the main concern about proposed revised guidelines is not so much their scientific content, but the fact that, if adopted, serious discrepancy between British and American laboratory practices could result, with potentially embarrassing consequences.

It could, for example, be cheaper to send a research worker to the US to carry out a set of experiments requiring little more than a conventionallyequipped laboratory bench, than to instal-or even hire-facilities providing the higher physical containment levels required to carry out the same experiment in the UK.
Such embarrassment is likely to be reinforced if other European countries, most of which have so far followed the British guidelines as suggested by the Williams Committee in 1976, decide to break ranks and, in line with the US, introduce significantly lower containment levels (as the French are, indeed, now proposing to do).

If, for example, Germany decides to introduce less stringent guidelines, British scientists working at the European Molecular Biology Laboratory at Heidelberg, which operates under German laws, may find they are permitted to carry out experiments which they are unable to do at home.

In such a situation, GMAG could find itself caught in a more difficult dilemma than that which it has already faced over confidentiality. For while responding-reasonably-to demands from scientists to rationalise containment levels, public confidence requires that it must not be seen to be responding to outside, and particularly industrial, pressure.

The members of GMAG are conscious that if they impose too harsh a set of restrictions on industrial research programmes as compared with other countries, companies will merely transfer their research programmes-and their revenue-earning potential-elsewhere; "and we don't want a repeat of the penicillin story", according to one GMAG member.

However, the Williams Report, which itself followed the public discussions generated by the Ashby report of 1975 and received evidence from a wide range of bodies, is still less than two years old. Any major attempt to re-draft its proposals at this stage is likely to be seen as premature, if not by scientists at least by the public, to whom some of the more fanciful possibilities (and dangers) of genetic engineering have only recently come home.

Indeed, it is one of GMAG's strengths that, through the trade union and "lay" representatives, it is able to take public concern directly into consideration (thus avoiding the major confrontations between scientists and the public that have, for example, occurred in the US).

Yet as the pressures on GMAG increase, so the tensions between its constituent parts may become more difficult to control. Such tensions arise partly from the ambiguous nature of GMAG itself, seen by some as an unfortunate, if necessary, part of scientific bureaucracy, and by othersincluding the trade unionists-as a successful model of public participation in research policy, with potential applications in other areas.

Disagreement over how to handle the confidentiality issue has already brought these tensions to the surface. And while there is little criticism of the bchaviour of the trade union representatives on scientific aspects of GMAG's work, they have already been accused of trying to make "political" points out of issues such as the future of the Ministry of Defence's Microbiological Research Establishment at Porton Down (part of which is likely to be transferred to the Department of Health and Social Security for carrying out top risk experiments requiring Category IV containment levels).

The political temperature of the debate has been raised by the recent decision of the British Society for Social Responsibility in Science to set up a genetic engineering group. This has already attacked the "complacent" attitudes of many scientists towards the safety aspects of such work. And the BSSRS group also feels that safety guidelines should have the force of law.

These issues will also undoubtedly be aired at the public hearings into genetic engineering soon to be held by the House of Commons Select Committee on Science and Technology. Reactions to the decision to organise these hearings vary; some are wary of the effects that renewed public exposure will have, and of possible "anti-scientific feeling" on the committee, while the BSSRS group has, in contrast, given the decision enthusiastic support.

But there are a number of important issues in need of attention. One of these is the make-up of GMAG itself, whose members are due to be reappointed at the end of 1978. Many would like to see more scientists on the group, particularly experts in fields of research not adequately covered at the moment. And there is still a residual unhappiness that although GMAG has two ASTMS representatives, there is no member of the Association of University Teachers acting in a representative capacity.

Another issue to which the Select Committee may give its attention is the intensive, quantitative study of the potential hazards of genetic engineering rescarch. So far, despite an apparent commitment both in the US and the UK to the need for such work, little has yet been done by the scientific community actively to promote it.

GMAG is due to present its first annual report to Mrs Shirley Williams, Secretary of State for Education and Science, in a few weeks time. One thing is already clear: that GMAG's role is likely to become both more important and more difficult. As Sir Gordon says: "If anything, our 'political' problems are not going to die out, they will increase; and not because anything is going wrong, but because it is in the nature of the animal." 